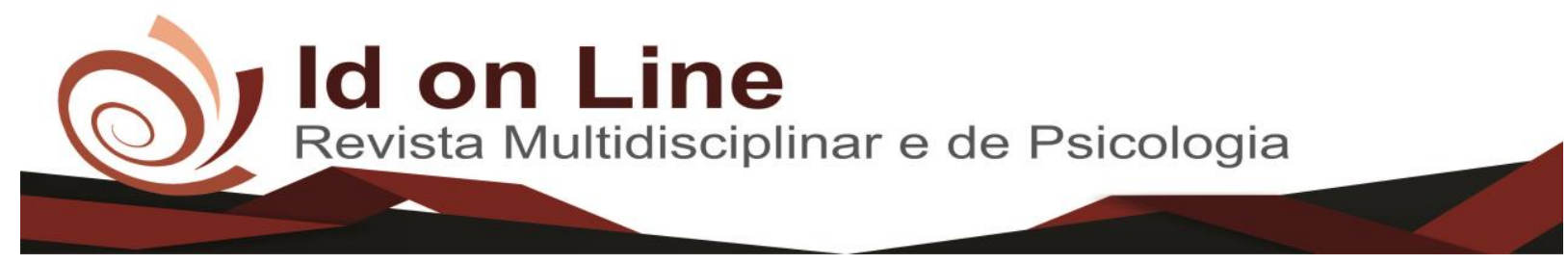

Artigo

\title{
Ações sustentáveis e suas implicações no trabalho: Uma análise acerca do uso de copos descartáveis
}

\author{
Cláudio Alberto de Sá Quirino ${ }^{1}$; Renatha Dayane Cabral de Araújo Ramos ${ }^{2}$
}

\begin{abstract}
Resumo: Este estudo aborda, no viés do Colegiado de Engenharia Elétrica da Univasf (Juazeiro/BA), a relevância estratégica de ações sustentáveis no consumo de copos descartáveis, considerando reflexos na conscientização dos servidores, assim como na redução do consumo dos resíduos. Para tanto, o estudo foi fundamentado em estudo de caso, a partir da análise de dados de uso dos copos descartáveis no lócus de investigação e gastos despendidos com sua aquisição. Da exploração dos dados e do recorte bibliográfico, concluiu-se que, dentre as ações implementadas na Univasf, a exemplo da distribuição de canecas e promoção de campanhas sobre o consumo de copos descartáveis, produziram impactos quanto às metas para uma gestão sustentável, além de refletir nos orçamentos de aquisição deste material, no entanto ainda é preciso estimular mecanismos que conscientizem sobre benefícios da minimização do consumo dos copos descartáveis, tornando essas campanhas mais assertivas. Nota-se, por meio dos estudos, que as ações sustentáveis e a conscientização contínua dos servidores implicam em reflexos positivos nos gastos com a aquisição de copos descartáveis para Univasf e setores acadêmicos. Os dados evidenciam que a quantidade dos copos descartáveis contabilizou um gasto, em 2016, de R $\$ 7.271,61$, cerca de $9 \%$ no orçamento com materiais de consumo na Univasf. Por isso que, analisando o impacto ambiental produzido e custos de aquisição dos materiais, as propostas sustentáveis constituem-se como alternativas viáveis para construir-se uma cultura socioambiental significativa.
\end{abstract}

Palavras-chave: Sustentabilidade; Copos Descartáveis; Proposições; Univasf; Cenel.

\section{Sustainable actions and their implications at work: An analysis of the use of disposable cups}

\begin{abstract}
This study deals with the strategic relevance of sustainable actions in the consumption of disposable cups, considering the awareness of the servers, as well as the reduction of waste consumption, in the bias of the Univesf Electric Engineering College (Juazeiro / BA). To do so, the study was based on a case study, based on the analysis of the use of disposable cups in the research locus and expenditures expended with its acquisition. From the analysis of the data and the bibliographic clipping, it was concluded that among the actions implemented at Univasf, such as the distribution of mugs and the promotion of campaigns on the consumption of disposable cups, produced impacts on the goals for sustainable management, besides However, it is still necessary to stimulate mechanisms that raise awareness of the benefits of minimizing the consumption of disposable cups, making these campaigns more assertive. It is noted through the studies that sustainable actions and the continuous awareness of the servers imply positive impacts on the expenses with the acquisition of disposable cups for Univasf and academic sectors. The data show that the amount of disposable cups accounted for an expense in 2016 of $\mathrm{R} \$$ $7,271.61$, about $9 \%$ in the consumption materials budget at Univasf. That is why, by analyzing the environmental impact produced and the costs of acquiring the materials, sustainable proposals constitute viable alternatives to build a meaningful socio-environmental culture.
\end{abstract}

Palavras-chave: Sustainability; Disposable cups; Propositions; Univasf; Cenel.

\footnotetext{
${ }^{1}$ Mestrando em Administração Pública (Profiap). Bacharel em Administração (Univasf). Pós-Graduado em Gestão de Pessoas (Unopar). Servidor Público Federal - Colegiado de Engenharia Elétrica (Cenel/Univasf). E-mail: claudio.quirino@univasf.edu.br

2 Administradora pela Universidade Federal do Vale do São Francisco (2014); Enfermeira pela Universidade de Pernambuco; Especialista em Saúde do Trabalhador (2015); Especialista em Gestão em Saúde UNIVASF (2016); Discente da Pós - Graduação em Gestão Pública (UNIVASF). E- mail: renathacabral8@gmail.com
} 


\section{Introdução}

Enquanto instrumento de difusão do conhecimento, sensibilização social, de empenho na conscientização ambiental e da produção científica, a universidade tem se constituído como importante agente de desenvolvimento e compartilhamento de experiências acerca da gestão sustentável (GUERRA et al., 2015), incentivando melhorias e uma maior participação efetiva da comunidade acadêmica na definição de soluções para tornar mais salutar o ambiente onde se desenvolve o trabalho realizado.

No que concerne às medidas e políticas sustentáveis, as instituições de ensino têm buscado cada vez instituir práticas que colaborem evidentemente com a questão da conservação da natureza. Sem dúvida, no tocante ao desempenho de atividades de ensino, pesquisa e extensão, universidades têm registrado um desafio preocupante na geração de resíduos sólidos (CARBONARI; PEREIRA, 2015).

Mediante os dados da Associação Brasileira de Empresas de Limpeza Pública e Resíduos Especiais (Abrelpe), no ano de 2016, o Brasil contabilizou um aumento na produção de resíduos sólidos, que atingiu a marca de 79,9 milhões de toneladas. Por outro lado, ainda são muito incipientes e deficientes os mecanismos de tratamento e destinação adequada dos resíduos sólidos no país, agravando a contaminação de solos, da água potável e refletindo em um bem-estar da sociedade (BOFF, 2017).

Dentre os principais resíduos sólidos observados na composição do lixo urbano brasileiro, os copos descartáveis ocupam posição de destaque, ainda mais considerando o tempo prolongado de decomposição no ambiente e as dificuldades na reciclagem do resíduo, tendo em vista o retorno mínimo do seu processo de destinação. No tocante à universidade, percebe-se que é grande o consumo de copos descartáveis no exercício e no desempenho das atividades administrativas, contribuindo para o crescimento dos dados sobre a geração de resíduos sólidos urbanos (RSU).

O estímulo para a proposição das ações de gestão sustentável dentro dos ambientes acadêmicos é fenômeno recente, embora algumas iniciativas e esforços esporádicos sejam descritos na literatura; preocupação com preservação ambiental parte de pressupostos do atendimento às metas e aos objetivos da sustentabilidade estabelecidos para a organização (MUNCK; BANSI; GALLELI, 2016). 
Nesse sentido, a motivação para redução do consumo de copos descartáveis nas universidades, públicas e privadas, é uma atividade que deve ser disciplinada, enérgica e contínua, uma vez que, especialmente em tempos de "aperto financeiro", a sua aquisição implica em reflexos no orçamento acadêmico.

Na Fundação Universidade Federal do Vale do São Francisco (Univasf), a partir da instituição do Plano de Logística Sustentável (PLS) e também da Agenda Ambiental da Administração Pública (A3P), ambos os documentos publicados em 2016, observam-se iniciativas estratégicas para implantação das ações para a promoção da conscientização sustentável quanto ao uso dos copos descartáveis, especialmente na distribuição aos servidores do "Kit Univasf Sustentável", composto por caneca (material com um menor tempo de decomposição e fácil tratamento de reciclagem) e sacola biodegradável.

Unidades setoriais dentro das universidades, os Colegiados Acadêmicos, podem exercer um papel significativo, em caráter de conscientização dos servidores, na proposição das ações com forte tendência para definir a cultura sustentável.

Assim, no Colegiado de Engenharia Elétrica (CENEL), lócus de investigação do estudo, onde é perceptível um uso considerável de copos descartáveis, enxerga-se a possibilidade de definição de um plano de ações sustentáveis que contribuam, em nível micro, para maior atingimento de objetivos de sustentabilidade, refletindo na minimização do valor orçamentário alocado para a compra de material de consumo administrativo do Colegiado e na produção dos resíduos.

Nesse espaço de investigação, fundamenta-se o objetivo da pesquisa, que é discutir, na perspectiva do CENEL/Univasf (Juazeiro/BA), a proposição das ações sustentáveis para a conscientização dos servidores quanto ao consumo de copos descartáveis, gerando retorno econômico, com capacidade para a possível reprodução em outras unidades acadêmicas.

Outros objetivos que estão delimitados na presente pesquisa são elaborar o levantamento bibliográfico acerca da sustentabilidade e da importância da prática da gestão sustentável nas universidades; divulgar o cenário do consumo dos copos descartáveis no CENEL/Univasf, assim como do percentual dos resíduos nos gastos com os materiais de consumo; divulgar mecanismos no atendimento a critérios de sustentabilidade e analisar as campanhas sustentáveis promovidas por esta instituição de ensino superior.

Com isso, busca-se elucidar o seguinte problema de pesquisa: qual o cenário atual do consumo de copos descartáveis no Colegiado Acadêmico de Engenharia Elétrica da Univasf - 
CENEL/Univasf, campus Juazeiro/BA, e quais medidas podem ser propostas para contribuir com a cultura sustentável neste Colegiado?

\section{Referencial teórico}

A sustentabilidade é a capacidade de se sustentar, de se manter. Uma atividade sustentável é aquela que pode ser mantida para sempre, continuamente e indefinidamente. Em outras palavras, a exploração de um recurso natural exercida de forma sustentável durará para sempre, não se esgotará nunca (BOFF, 2017)

Nesse sentido, Sociedade Sustentável é aquela que não coloca em risco os elementos do meio ambiente e o Desenvolvimento Sustentável. Para Freitas e Freitas (2016), Desenvolvimento Sustentável é aquele que melhora a qualidade da vida do homem na Terra ao mesmo tempo em que respeita capacidade de produção dos ecossistemas nos quais vivemos.

Justifica-se a abordagem do conceito de sustentabilidade com base em um enfoque transdisciplinar. À medida que a abordagem vem sendo desenvolvida, conceitos da Sustentabilidade e Desenvolvimento Sustentável continuam evoluindo (GAVIÃO et al., 2017).

O Desenvolvimento Sustentável procura a melhoria da qualidade de vida da sociedade com o uso racional e consciente dos recursos naturais. Enquanto o desenvolvimento sustentável pode requerer ações distintas em cada região do mundo, esforços para construir modelo de vida sustentável, requerem a integração de ações em três áreas (FREITAS; FREITAS, 2016):

Crescimento e Equidade Econômica: Sistemas econômicos interligados demandam uma abordagem integrada para promover crescimento responsável de longa duração, ao mesmo tempo em que assegurem que uma nação ou comunidade fiquem à margem do progresso e desenvolvimento.

Conservação de Recursos Naturais e Meio Ambiente: Para conservar a herança ambiental e recursos naturais para gerações futuras, soluções viáveis devem ser desenvolvidas com o objetivo de minimizar o uso de recursos, controlar a poluição e conservar os habitats naturais.

Desenvolvimento Social: No mundo, as pessoas precisam de emprego, alimento, educação, energia, serviço de saúde, água e saneamento. Enquanto discutem-se tais necessidades, a comunidade mundial deve também assegurar que a matriz de diversidade 
cultural e social e direitos trabalhistas sejam respeitados, e que os membros da sociedade estejam capacitados a participar na definição de seus futuros.

No presente contexto, considera-se que o sentido mais importante da gestão da sustentabilidade é que representa a justiça em relação às gerações futuras (MUNCK; BANSI; GALLELI, 2016). Levando em consideração essa perspectiva, é preciso refletir sobre a seguinte dúvida: Como podemos explorar conscientemente recursos naturais, visando à plena manutenção de processo produtivo e consumo humano, sem, no entanto, penalizar as gerações futuras? (MOTA, 2014, p. 9).

É possível desenvolver uma ideia de consumo sustentável que, por si mesma, implique em garantias para o futuro? É possível explorar recursos sem produzir tanto esgotamento dos solos, poluição e influência na qualidade de vida e do bem-estar social? Sem dúvida alguma, essas são as principais inquietações que povoam o imaginário humano há tempos: produzir o consumo contínuo sem agredir ao meio ambiente.

Consumo sustentável é aquele que utiliza os serviços e produtos que respondam às necessidades da sociedade trazendo melhoria na qualidade de vida, reduzindo o uso de recursos naturais, materiais tóxicos, produção de lixo e emissão de poluição no ciclo de vida, sem comprometer as gerações futuras (FREITAS; FREITAS, 2016). A sustentabilidade se relaciona à quantidade do consumo que pode continuar de forma indefinida, sem degradar os estoques de capital total, que é representada pelo somatório de capital material, capital humano e capital natural (BOFF, 2017).

Com base no levantamento teórico, observa-se grande necessidade de se estimular a prática da gestão sustentável em todos os segmentos sociais, buscando, de maneira resolutiva e a preservar os recursos naturais limitados, contribuir para a definição de mecanismos de proteção, de administração e de conservação do patrimônio natural. Para que o gerenciamento sustentável seja eficiente e assertiva, é preciso instigar nas pessoas o desejo de atentar-se para escassez de recursos naturais cada vez mais indiscriminadamente explorados, para os principais desafios que colocam em risco a própria sobrevivência e a evolução das gerações futuras. 


\section{Relevância da Gestão Sustentável nas universidades: ações e proposições estratégicas}

A responsabilidade sustentável tem desempenhado nas instituições da Administração Pública um papel estratégico para a manutenção e a continuidade de serviços públicos que são prestados à comunidade, sem, pois, agredir ao meio ambiente e ao entorno (CARBONARI; PEREIRA, 2015).

Por meio dos diversos desafios sustentáveis, da percepção do mundo acerca dos crimes e da consequente responsabilidade ambiental e desejo de proteção dos recursos naturais para futuras gerações, busca-se implementar ações pautados na sustentabilidade com uma capacidade de produzir impactos dentro da sociedade e configurações na cultura interna das empesas (GAVIÃO et al., 2017).

Nesse sentido, torna-se extremamente imprescindível implementar em todos os aspectos, organizações e os sistemas o modelo de gestão sustentável com a capacidade de gerar resultados extraordinários, incutir o senso de responsabilidade e compromisso nas pessoas e de agregar valor. Nos ambientes organizacionais, sustentabilidade e gestão socioambiental deixaram de serem analisadas como os centros de custos e impulsionam a reputação, imagem e a competitividade.

Por meio desse entendimento, a literatura tem se mostrado bastante otimista, longeva e abrangente acerca dos estudos de proposições da sustentabilidade dentro dos ambientes acadêmicos brasileiros, repercutindo no fortalecimento e também na configuração da cultura sustentável e gestão social.

Segundo essa lógica, a sustentabilidade passa a modelar a forma de prestar serviços nesses espaços, de enxergar o ambiente em que se executam atividades a partir de olhares mais nítidos. Torna-se cada vez mais comum observar dentro das universidades e instituições de ensino superior, públicas ou privadas, conexões e interações com enfoque na ação e definição de práticas sustentáveis (WARKEN; HENN; ROSA, 2014).

O papel assumido pelas universidades no que tange à gestão sustentável aborda duas diferentes esferas: (i) a esfera educacional, refletida na formação de profissionais e pesquisadores, que, em caráter interdisciplinar, são conscientizados a adotarem ações sustentáveis no processo de investigação científica; e (ii) a esfera gerencial, que trata do Sistema de Gestão Ambiental (SGA) implantado pela universidade em setores acadêmicos (suporte, coordenação e gestão), por meio de emissão e publicidade de documentos que regimentem 
conscientização sustentável, com a definição de modelos e dos exemplos práticos de gestão sustentável para a sociedade.

As universidades possuem papel histórico de transmissão do saber científico. Através do acúmulo de conhecimento e elaboração de técnicas e tecnologias mais sofisticadas ao longo do tempo, a natureza vem sendo cada vez mais explorada, alcançando ações exorbitantes de extrativismo, e isso vem se perdurando ao longo de várias gerações (MATEUS; BRAGANÇA, 2016).

A cultura de exploração exacerbada é preocupante no cenário globalizado, onde as relações de consumo e de produção de produtos e serviços encabeçam o rol das principais atividades humanas depredatórias dos recursos naturais; com isso, pensando no contexto extremamente inquietante e desafiador, acredita-se que por meio da educação a consciência sustentável possa ser despertada (BOFF, 2017).

Parece evidente que a mudança de comportamento e mentalidade humanos ocorre no momento em que as universidades e as instituições educativas diversas apresentam a preocupação com o desenvolvimento sustentável, com a forma como está produzindo conhecimento para a sociedade em geral, tornando-a mais crítica e participativa, ultrapassando a percepção de mero reprodutor de informação sem qualquer responsabilidade de motivar e transformar o cenário de exploração e de contrastes ambientais.

Embora desempenhe um papel essencial na busca pela sustentabilidade, a educação "sozinha" não levará ao objetivo proposto, tendo em vista que é preciso estimular o interesse de outros agentes estratégicos com capacidade de atuar na proposição de ações sustentáveis transformadoras. É preciso, nesse mesmo viés, garantir o envolvimento, engajamento e a participação no processo de construção, execução e monitoramento de mecanismos sustentáveis (GAVIÃO et al., 2017) que efetivamente produzam reflexos expressivos na comunidade e no meio.

Para tanto, além de atividades acadêmicas que propiciem a educação ambiental e de gestão social na comunidade acadêmica, bem como a formação do pensamento crítico acerca da exploração racional de recursos, é necessário que as universidades assumam o compromisso de orientar e de conduzir, em conjunto com agentes sociais de desenvolvimento, proposições sustentáveis, a exemplo das medidas que contribuam para o uso consciente de papel, pilhas, pincéis, repositores de tinta e também cartuchos, dentre outros resíduos sólidos que elevam a 
geração de lixo, a contaminação do ambiente e soluções de reciclagem e destinação adequadas de cada material, em particular.

Além da consciência sustentável para os servidores no exercício da prestação do conjunto de serviços administrativos, cujo comportamento reflete no consumo alto de recursos não recicláveis dentro de ambientes acadêmicos, contribuindo, assim, para a ruptura da efetividade das ações implementadas, a universidade se destaca em função da formação de profissionais conscientes da função que devem desempenhar na proteção ambiental, priorização desses assuntos nas agendas governamentais, no exercício de convencimento social acerca da importância dessas práticas ou na proposição de políticas públicas sustentáveis (FREITAS; FREITAS, 2016; BOFF, 2017).

As universidades são em parte responsáveis pela formação dos futuros líderes, políticos, dos cientistas, formadores de opinião, especialistas e agentes de mudança que ocuparão cargos de destaque nos governos, setores públicos, nas empresas e em outras organizações privadas (PEREIRA et al., 2014).

Por isso que se deve enxergar a universidade como agente estratégico que molda personalidade e comportamentos dessas profissionais e, ao mesmo tempo, investem no reconhecimento dos retornos que as ações e proposições executadas produzem para a sociedade. A gestão sustentável tem alcançado patamar elevado dentro das universidades, tendo em vista a observância de desafios na gestão dos impactos provenientes do consumo desenfreado de materiais e, consequentemente, dos reflexos que essas atitudes produzem no crescimento, expansão e composição orçamentária de alocação de recursos.

\section{Análise do impacto ambiental resultante do consumo de copos descartáveis}

O consumo de copo descartável tem preocupado consideravelmente as organizações, ainda mais as universidades, já que o referido material de consumo apresenta tempo de decomposição elevado (entre 250 e 400 anos); outro argumento para busca e execução de políticas estratégicas de sustentabilidade nesses espaços de mudança social é também o atendimento a pressões exercidas pela sociedade no que compete à proteção ambiental e manutenção do equilíbrio do entorno natural (MACEDO et al., 2016). 
Atualmente, segundo os dados resgatados nas indústrias, foram produzidos no Brasil, em 2016, cerca de 8.000 toneladas mensais, um número que equivalente a 96.000 ton/ano de copos descartáveis de poliestireno. Segundo os dados do setor, antes da edição da norma de padronização do referido produto, a produção nacional era de 6.000t/mês, valor significativo para se observar o número de copos que são descartados, muitos sem qualquer tratamento, despejados no ambiente (GAVIÃO et al., 2017).

Observa-se, diante da discussão acerca da sustentabilidade, o conjunto de desvantagens e dos impactos do uso de copos descartáveis, ainda mais analisando os métodos da produção, que, por si mesmos, deveriam desestimular o uso desse item e substituição por recurso reciclável (CORRÊA; HEEMANN, 2016). No caso da produção de copo descartável, são gastos, em média, 8 gramas de poliestireno (PS) ou polipropileno (PP), $6 \mathrm{Wh}$ de energia elétrica e também $500 \mathrm{~mL}$ de água. Além disso, a produção provoca uma considerável emissão de gás carbônico $\left(\mathrm{CO}_{2}\right)$, dentre outros responsáveis pelo desequilíbrio do efeito estufa, uma das formas de contribuição para o aquecimento do planeta (SPOLADORE; PRATES, 2011).

Outros estudos podem ser adicionados para abranger outras perspectivas do consumo de copos descartáveis. Uma pesquisa feita pelo Instituto de Química da Universidade Federal da Bahia (UFBA) apontou que os copos descartáveis feitos a partir de poliestireno (PS), quando em contato com substância quente (café ou chá, por exemplo), podem liberar estireno em quantidade acima do considerado seguro pelo Ministério da Saúde e conhecido pela Agência Internacional de Pesquisa do Câncer (IARC) como possível cancerígeno, capaz de trazer outros males (dores de cabeça, depressão, problemas neurológicos, dentre outros.) (CORRÊA; HEEMANN, 2016).

Apesar desse indicativo, o estudo não é conclusivo quanto à influência da desintegração do poliestireno e de seus derivados no organismo humano, devendo a investigação ser aprofundada e endossada por maior fundamentação de pesquisa.

No uso de copos de plástico, deve-se sempre levar em consideração que este material é produzido a partir de processos químicos no petróleo (poliestireno), que é uma fonte não renovável, poluente, e que implica grande impacto ambiental. Apesar de poder ser reciclado, a análise na literatura evidencia que é praticamente mínima a participação do poliestireno reciclado na produção de copos novos. Em virtude disso, nota-se que o produto descartável utiliza uma matéria-prima extrativa e não sustentável (CORRÊA; HEEMANN, 2016). 
Os copos descartáveis somente deixarão de ser um desafio constante para a natureza quando houver mudança arraigada e profunda de comportamento de quem consome o produto, da consciência acerca da preservação e das limitações de destinação e reciclagem do material. Consumir conscientemente significa atentar para os efeitos e implicações muitas vezes catastróficas que a atitude acarreta ao meio ambiente, aos profissionais e à sociedade como um todo (CASTRO; ALMEIDA; SILVA, 2012, p. 7).

Conforme discutido, o uso dos copos descartáveis representa à sociedade e ao meio ambiente uma séria ameaça à perpetuação do bem-estar e da qualidade de vida, decorrente do consumo alto associado à ausência de mecanismos estratégicos de forte atuação na conscientização das pessoas quanto à redução de impactos.

Logo, busca-se cada vez mais estimular a sua substituição por elementos que agridam com menor potencial o meio ambiente, que são facilmente reciclados e que promovem mudança e fortalecimento de uma cultura sustentável, inclusive com as implicações no custo de tratamento e no orçamento destinado à aquisição de copos descartáveis para empresas e, ao mesmo tempo, no investimento em proposições eficientes e reflexivas (MACEDO et al., 2016).

\section{Metodologia}

A Fundação Universidade Federal do Vale do São Francisco (Univasf), como instituição de ensino superior pública, localizada no sertão nordestino, tem como um dos principais objetivos, no contexto do propósito do presente artigo, promover o desenvolvimento regional. Daí, ações e atividades pautadas no consumo racional dos recursos naturais que estão disponíveis é algo importante para a atuação com excelência e responsabilidade pela Administração Pública, especialmente na seara da gestão sustentável.

Enquanto locus desta investigação, o Curso Acadêmico de Engenharia Elétrica da Univasf foi criado em atendimento à demanda identificada em consulta à sociedade da região do Vale do São Francisco, uma das iniciativas que precederam à implantação dos maiores campi, sediados em Petrolina (PE) e Juazeiro (BA). 
O curso, conforme os dados do Sistema de Registro e Controle Acadêmico (SRCA), com as informações de setembro de 2017, atende ao quantitativo de 295 discentes, distribuídos ao longo de cinco semestres.

Com base no âmbito de investigação in loco, o estudo foi fundamentado na pesquisa documental e bibliográfica, em uma perspectiva de estudo de caso, no que compete ao resgate e à análise de documentos institucionais que versam sobre a proposição de ações e de práticas sustentáveis, inclusive com reflexos no uso dos copos descartáveis na Univasf e conscientização de mudança, como, por exemplo, do Plano de Logística Sustentável (PLS, 2016) e também da Agenda Ambiental da Administração Pública (A3P, 2016).

No viés de pesquisa bibliográfica, os artigos científicos foram selecionados a partir da busca, por meio dos descritores: Sustentabilidade, Copos Descartáveis, Universidade, Propostas Sustentáveis. As bases de dados para a pesquisa teórica foram o Google Acadêmico, Scielo, Spell e Banco de Dissertações da Capes, com uma priorização para achados publicados entre 2013 a 2017, por autores nacionais.

\footnotetext{
Um estudo de caso é uma investigação empírica que investiga um fenômeno contemporâneo dentro do contexto da vida real, especialmente quando limites entre fenômeno e contexto não estão claramente definido (YIN, 2001 p. 33).
}

Conforme Yin (2001), esta pesquisa trata-se de um estudo de caso, por obter o diagnóstico do uso dos copos descartáveis no Colegiado de Engenharia Elétrica (Cenel) da Univasf e definir estrategicamente a proposição de ações sustentáveis também no âmbito deste Colegiado. Segundo Yin (2001), um estudo de caso é caracterizado por um estudo profundo e exaustivo dos fatos objetos de investigação, permitindo um amplo e pormenorizado conhecimento da realidade e dos fenômenos pesquisados. 


\section{Resultados e discussão}

Cenário institucional do consumo dos copos descartáveis e as suas implicações no orçamento

No desempenho das atribuições administrativas, as Universidades buscam prestar cada vez mais serviços eficientes, ágeis e de qualidade, e, muitas vezes para que atendam a critérios, é preciso atentar aos recursos ou bens da exploração (papel, plástico, pilhas, etc.) e, em contrapartida, oferecer retorno de proposições e ações sustentáveis para manutenção das suas atividades.

Com o foco nas preocupações e desafios da sustentabilidade, a Univasf, atuando em conjunto seus setores acadêmicos, tem garantido sua contribuição na preservação ambiental, com a execução de mecanismos sustentáveis, em especial para o consumo de copos descartáveis (SILVA, 2016).

As ações produzidas e executadas na instituição, com capacidade de direta e indiretamente repercutir no consumo de copos descartáveis, buscam priorizar a mínima ação de agressão ao meio ambiente, respeitando, também, a necessidade de conscientização dos servidores para diversas problemáticas do consumo desses resíduos. Conforme o entendimento, os dados e informações a seguir são extraídos de documentos disponibilizados pela instituição, em páginas institucionais online.

Com base na Tabela 01, em 2016, foram distribuídos, na Univasf, total de 3.805 pacotes de 100 unidades de copos descartáveis - considerando ambos os volumes de $200 \mathrm{~mL}$ (água) e $50 \mathrm{~mL}$ (cafezinho) - contabilizando o valor de 380.500 copos descartáveis.

Tabela 1: Distribuição de copos descartáveis pela Univasf aos setores internos (2016).

\begin{tabular}{cccccc}
\hline $\begin{array}{c}\text { Item } \\
\mathbf{1 0 0} \text { unidades }\end{array}$ & $\begin{array}{c}\text { Quant. } \\
\text { Anual }\end{array}$ & Unidade & $\begin{array}{c}\text { Valor unit. } \\
(\mathbf{R} \$)\end{array}$ & $\begin{array}{c}\text { Valor total } \\
(\mathbf{R} \mathbf{\$})\end{array}$ & $\begin{array}{c}\text { Produto } \\
\text { Sustentável }\end{array}$ \\
\hline $\begin{array}{c}\text { Copo Descartável } \\
200 \mathrm{~mL}\end{array}$ & 3.120 & Pacote & 2,17 & $6.767,91$ & $\mathrm{NÃO}$ \\
$\begin{array}{c}\text { Copo Descartável } \\
50 \mathrm{~mL}\end{array}$ & 685 & Pacote & 0,83 & 503,70 & NÃO \\
\hline
\end{tabular}

Fonte: Plano de Logística Sustentável - PLS (2016, p.31). 
No tocante ao número de copos descartáveis consumidos pelos setores demandantes, apesar dos autores deste estudo não identificarem publicações deste quantitativo em outras universidades para efeito de comparação, é visível um número bastante significativo, elevando os gastos com a aquisição (Tabela 01) e o acondicionamento desses resíduos na Universidade.

Os dados evidenciam que esse número de copos descartáveis alocados aos setores demandantes contabilizou um gasto anual de $\mathrm{R} \$ 7.271,61$ (sete mil, duzentos e setenta e um reais, sessenta e um centavos), representando cerca de $9 \%$ no orçamento com os materiais de consumo, segundo dados da Pró-Reitoria de Planejamento e Desenvolvimento Institucional (Propladi), em 2016.

De acordo com resultados de Silva (2016), o quadro de pessoal é composto por 848 servidores, sendo 487 docentes efetivos e 361 técnicos-administrativos em educação (TAE) e, considerando o número dos servidores ativos na instituição, calculou-se um consumo anual de 364 copos descartáveis por cada servidor no ano de 2016. Em relação ao ambiente do CENEL, são 20 (vinte) docentes distribuídos entre as diversas áreas do conhecimento e 1 (um) servidor técnico-administrativo.

O valor representa um consumo de cerca de 1 (um) copo descartável de poliestireno por dia, dados que, à primeira vista, parecem insignificante, porém o uso desses resíduos sólidos deve crescer com um aumento dos discentes e docentes, deixando pouca margem de espaço para as ações vigentes de sustentabilidade, já que as metodologias de tratamento e de reciclagem dos copos de poliestireno são poluentes, complexas e, no âmbito institucional, atendem a prazos definidos.

Além disso, conforme dados do Relatório do Plano de Logística Sustentável de 2016, publicado em maio de 2017, avaliando impactos de ações sobre o uso de copos descartáveis apontou um aumento do consumo do copo descartável de $200 \mathrm{~mL}$, com a variação de $16 \%$ em 2016, quando comparado com 2015.

Esses dados levam a concluir que deve haver maior atenção às medidas para redução do uso do copo descartável de $200 \mathrm{~mL}$ na Univasf. Por outro lado, observa-se uma redução no consumo de copos de $50 \mathrm{~mL}$, considerando o mesmo período, com queda de 24\% (PLS, 2017).

Para Silva (2016, p. 18), o número de consumo de copos descartáveis de poliestireno na universidade tende a apresentar incrementos expressivos, já que o servidor passa dentro da instituição (cerca de oito horas) e também contabilizando as horas que excedem o horário 
normal de trabalho, para alguns setores específicos em épocas acadêmicas sazonais (período de matrículas, de realização de grandes eventos, etc.).

Além das implicações nos custos orçamentários para a aquisição de materiais de consumo interno, que é bastante significativa para a composição de custos, observa-se uma problemática que reflete na geração cada vez mais indiscriminada de resíduos sólidos na universidade.

Considerando uma análise setorial, os Colegiados Acadêmicos também têm apontado um consumo de copos de poliestireno considerável, contribuindo, assim, para a maximização da produção de resíduos sólidos de plástico. Para a Cartilha da Agenda Ambiental da Administração Pública (A3P), o plástico se constitui, tal como o papel, em um dos principais resíduos sólidos gerados pela Administração Pública, inclusive universidades, na forma, principalmente, de copos plásticos utilizados para o consumo de água e café (SILVA, 2016, p. $70)$.

Na seara setorial, o Colegiado Acadêmico de Engenharia Elétrica (CENEL), locus da pesquisa e da proposição de ações sustentáveis, registrou, gastos de 3 a $10 \%$ com a compra dos copos descartáveis de poliestireno, considerando os meses de setembro a novembro; os dados da Tabela 2 foram resgatados no Sistema para Registro e Pedido ao Almoxarifado - canal online, por onde podem ser consultados, comparados e emitidos relatórios mensais de materiais de consumo dos Colegiados Acadêmicos e outros setores internos.

Tabela 2: Valores gastos com materiais de consumo diversos e com copos descartáveis do Cenel (setembro a novembro de 2017).

\begin{tabular}{|c|c|c|c|}
\hline MÊS DE REFERÊNCIA & $\begin{array}{c}\text { CUSTO } \\
\text { MATERIAL DE } \\
\text { CONSUMO (R\$) }\end{array}$ & $\begin{array}{c}\text { CUSTO MENSAL DE } \\
\text { COPOS } \\
\text { DESCARTÁVEIS } \\
(\mathbf{R} \$)\end{array}$ & $\begin{array}{c}\text { PERCENTUAL DE } \\
\text { GASTOS COM } \\
\text { COPOS } \\
\text { DESCARTÁVEIS } \\
(\%) \\
\end{array}$ \\
\hline SETEMBRO & 723,02 & 23,98 & 3,31 \\
\hline OUTUBRO & 318,90 & 34,92 & 10,95 \\
\hline NOVEMBRO & 482,90 & 17,48 & 3,61 \\
\hline
\end{tabular}

Fonte: Propladi (2017).

Conforme canal de registros do Colegiado Acadêmico de Engenharia Elétrica, são solicitados, mensalmente, 10 pacotes de copos de poliestireno para atendimento das atividades administrativas (professores, visitantes e assistente administrativo). 
Dessa forma, seguindo o mesmo raciocínio anterior, são 1.000 unidades que são consumidas por mês e 12.000 unidades, anualmente. O Colegiado dispõe de 21 servidores ativos em exercício, logo o consumo médio mensal por cada servidor é de 48 copos descartáveis, praticamente um uso de dois copos por dia de trabalho.

Quanto aos gastos do Colegiado com o material de consumo (Tabelas 2 e 3), copos descartáveis e percentual de despesas com resíduos, considerando os meses de setembro a novembro de 2017, segundo os dados extraídos do sistema de registros e pedidos, setembro e novembro, registraram percentuais estáveis, com registros de 3,31\% e de 3,61\%; o mês de outubro praticamente triplicou a proporção, registrando 10,95\%, porém com uma menor despesa com material de consumo.

$\mathrm{O}$ percentual maior justifica-se em respeito ao número de reuniões ordinárias do Colegiado e das Comissões Estruturantes, já que, no período de fechamento de semestre e deliberações sobre casos de matrícula e das aprovações especiais, aumentam o número de encontros dos professores e, por isso, o número de consumo de copos descartáveis aumenta.

Tabela 3: Orçamento para material de consumo do Cenel Univasf (2013 - 2017).

\begin{tabular}{cc}
\hline ANO DE REFERÊNCIA & $\begin{array}{c}\text { ORÇAMENTO PARA MATERIAL DE } \\
\text { CONSUMO (R\$) }\end{array}$ \\
\hline 2013 & $25.146,40$ \\
2014 & $28.230,08$ \\
2015 & $29.254,71$ \\
2016 & $31.426,75$ \\
2017 & $27.958,80$ \\
\hline
\end{tabular}

Fonte: Propladi (2017).

É válido destacar que o orçamento destinado às despesas com gastos com material de consumo para o Colegiado de Engenharia Elétrica para 2017 (Tabela 3), conforme os dados fornecidos pela Propladi, sofreu uma brusca redução em relação ao ano de 2016 e, assim, consta de $\mathrm{R} \$ 27.958,98$ (vinte e sete mil, novecentos e cinquenta e oito reais, noventa e oito centavos). Essa perda de investimento em material para o uso administrativo do Cenel demonstra e justifica o impacto positivo que a redução no consumo de copos descartáveis, do ponto de vista sustentável e econômico.

Partindo das variantes observadas nas duas tabelas, percebe-se um custo para a aquisição de copos descartáveis para Colegiado de Engenharia Elétrica (Cenel) reduzido em detrimento 
do orçamento destinado para outros materiais de consumo. Entretanto, é a sustentabilidade pautada no tempo de decomposição do item, em especial, que eleva a pesquisa a uma justificativa de proposição de ações estratégicas para a conscientização dos servidores.

Importante se faz destacar que essa necessidade de ações sustentáveis no âmbito do Colegiado Acadêmico decorre da normatização da busca por indicadores nos órgãos da Administração Pública. Assim, desde o ano de 2012, foi instituído na Univasf o "Programa de Gestão Ambiental", com o objetivo de implementar práticas sustentáveis na universidade, tendo como um dos indicadores a gestão adequada dos resíduos, dentre eles o copo descartável (SILVA, 2016, p. 72 ).

Desde a programação e as atualizações contínuas, programas sobre a gestão sustentável vêm norteando as abordagens desenvolvidas pelos setores internos e pela comunidade acadêmica, gerando resultados e reações positivas em algumas áreas, mas reconhece-se que ainda é preciso avançar mais no desenvolvimento das ações e uso contínuo de ferramentas de conscientização social.

A finalidade sustentável aliada à redução de recursos orçamentários, ainda mais em tempos de escassez econômica e queda de investimentos do Governo Federal dentro da Universidade, promovem impactos positivos na quantidade de lixo administrativo produzido, coleta seletiva e destinação dos materiais. Pensando nas relações construídas no cenário acadêmico, a Univasf promove, desde 2013, uma campanha estratégica de distribuição de canecas e de kits sustentáveis.

O "Kit Sustentável” busca atentar para as ações de conscientização e a sensibilização de servidores, em respeito aos indicadores de sustentabilidade para órgãos da Administração, implicando no consumo de caneca permanente como forma de substituição ao consumo crescente de copos descartáveis de poliestirenos analisados nos diversos levantamentos e relatórios pela Propladi.

Segundo dados fornecidos, desde o período em que foi implantado o programa, foram distribuídas cerca de 2.500 canecas entre os servidores, os estagiários e terceirizados que exercem funções administrativas. $\mathrm{O}$ objeto da ação sustentável consistia em canecas de cerâmica, com diâmetro de 7,5 cm e a altura de 10 cm (SILVA, 2016, p.79).

A face da frente das canecas apresenta o desenho de pinturas rupestres, tendo sempre abaixo o nome "UNIVASF". O verso da caneca apresenta a frase "Copo Descartável" e o 
desenho da mão com o polegar apontado para baixo (traduz uma concepção de "não curti") expressão contemporânea e facilmente identificável dentro do contexto.

Uma das laterais das canecas apresenta a marca em alusão ao Parque da Serra da Capivara. (SILVA, 2016, p.79). A sacola que acompanha a caneca é produzida com material biodegradável, enlaçada como um presente especial para os servidores, conforme Figura 1:

Figura 1: Kit Sustentável para os servidores da Univasf.

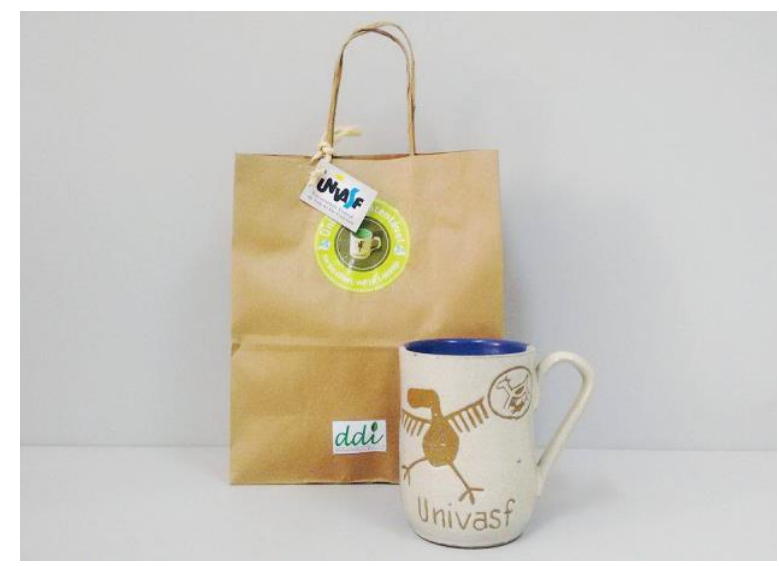

Fonte: Propladi (2017).

Dentre os objetivos desta proposta, encontram-se: proteger o meio ambiente; reduzir os gastos com a aquisição de copos descartáveis; ampliar a integração entre campi da Univasf, a partir da produção artesanal de objeto que promoveu a identidade do campus de São Raimundo Nonato (PI); valorizar cada servidor pelo seu tempo de colaboração, por meio da entrega de presente (caneca permanente); promover a conscientização dos servidores sobre o nível de consumo de recursos naturais na Univasf (água, energia, copos descartáveis, papel, etc); e contribuir para a adequação da Univasf à legislação ambiental (SILVA, 2016).

Percebe-se que esta ação cumpre o estabelecido pelas normativas que orientam a prática de programas sustentáveis nas universidades de nível federal. As diversas normativas são expedidas por órgãos do governo visando boas práticas de sustentabilidade e também racionalização de materiais. Como exemplo, cita-se a Instrução no 10/2012 - emitida pela Secretaria de Logística e de Tecnologia da Informação do Ministério do Planejamento, Orçamento e Gestão, que estabeleceu as regras para que a Administração Pública Federal elaborassem Planos de Gestão de Logística Sustentável (art. 16, do Decreto no 7.746/2012) (SILVA, 2016, p. 78). 
Seguindo o que diz a lei acerca da sustentabilidade, a Univasf instituiu o Plano de Logística Sustentável (PLS), estabelecendo para consumo dos copos descartáveis as seguintes recomendações: preferência para copos produzidos com os materiais que propiciem a reutilização ou a reciclagem com vistas a minimizar os impactos ambientais; e implementar campanhas de sensibilização para conscientizar os servidores a reduzirem o uso de copos descartáveis.

Após a discussão extensa acerca dos estímulos desempenhados pela Univasf quanto aos indicadores estratégicos de sustentabilidade, inclusive com reflexo sobre os Colegiados Acadêmicos, cumpre-se, aqui, a proposição de elencar algumas ações sustentáveis facilmente aplicáveis no contexto setorial e com capacidade de reprodução em outros Colegiados da instituição.

\section{Ações sustentáveis para a redução do consumo de copos descartáveis no Colegiado Acadêmico de Engenharia Elétrica da UNIVASF}

É preciso discutir propostas que estimulem conscientização e a sensibilização das pessoas quanto aos problemas e aos desafios da sustentabilidade, ainda mais no contexto das universidades, públicas e privadas, difusoras de conhecimento e formadoras de cidadãos conscientes, racionais, engajados e participativos.

O objetivo central é disseminar o saber teórico permeado de iniciativas para a definição, execução e manutenção de ações sustentáveis no viés do Colegiado de Engenharia Elétrica da Univasf (Cenel), analisando os aspectos fundamentais da cultura do setor e de comportamentos de servidores lotados nesse lócus de estudo.

Essas ações são justificadas em função dos principais entraves e dificuldades que são observadas no consumo do copo descartável, analisando seus impactos negativos produzidos no meio ambiente e na sociedade em geral. Atualmente, o copo descartável é o resíduo sólido urbano menos reciclado ao redor do planeta e a mesma realidade nota-se no Brasil, onde centros de tratamento de resíduos sólidos ainda não estão tecnologicamente preparados para exercitarem a abordagem de destinação (CORRÊA; HEEMANN, 2016).

Uma das maiores motivações disso é, além da incipiência tecnológica, o baixo custo de mercado. As empresas, bem como as cooperativas de reciclagem chegam a pagar até $\mathrm{R} \$ 0,20$ 
pelo quilo do copo usado. Além disso, por meio da proposição de práticas sustentáveis provenientes da substituição dos copos descartáveis por outros itens com o menor potencial de agressão ao meio ambiente, observa-se o grande impacto na Gestão Social, já que a Sustentabilidade perpassa a concepção de qualidade de vida e bem-estar da sociedade (MACEDO et al., 2016).

Pensar na Gestão Socioambiental, enquanto reflexo dessas ações, traz para a sociedade um pensamento de manutenção da qualidade do meio em que vive, onde se desenvolve (CORRÊA; HEEMANN, 2016), também de continuidade dos sistemas ecológicos que garantem a sobrevivência do ser humano.

Degradar o meio ambiente com o descarte de copos de poliestireno provoca a ruptura na cadeia de bem-estar da sociedade, possibilitando, em longo prazo, menor qualidade de vida. É por isso, dentre outras motivações, que o discurso da Gestão Socioambiental tem sido vantajoso e necessário para a construção da sociedade consciente, racional e participativa nas questões ambientais (MACEDO et al., 2016).

Nesse sentido, no que compete à proposição de estratégias sustentáveis para universidades, foram identificadas as seguintes práticas, após análise da literatura existente:

1. Copos de papel: Copos de papel decompõem mais rapidamente quando em contato com o ambiente em relação aos copos descartáveis produzidos com os substratos de petróleo (poliestireno), além de apresentarem facilidades na hora da reciclagem, já que normalmente o valor de venda do papel é superior ao do plástico nos centros de tratamento e reciclagem brasileiros, incentivando a gestão e recolhimento desses resíduos, inclusive no cenário acadêmico;

2. Copos de vidro temperado: Estes não sofrem rupturas com facilidade, além de serem reciclados facilmente e representar menor perigo cortante, quando quebrado, já que há fragmentação e centelhas de pedaços;

3. Copos descartáveis biodegradáveis: Segundo dados do site Recicláveis (2017), já existem empresas especializadas na produção de copos biodegradáveis que se decompõem entre 40 a 120 dias, garantindo menor risco ao meio ambiente, porém a sua acessibilidade é dispendiosa em relação aos copos descartáveis de poliestireno, mas compensa do ponto de vista da redução da geração de resíduos sólidos nocivos. Apesar desta opção ser ainda pouco utilizada dentro das empresas e universidades, do ponto de vista do seu custo de aquisição, o seu uso 
compensa especialmente quando a universidade conscientizar e mobilizar seus servidores para a redução de consumo de copos descartáveis, refletindo em menos agressão ao meio ambiente.

Os programas de conscientização, associados a uma contínua efetividade no uso por parte do corpo de servidores institucionais, impactam no orçamento para a aquisição dos copos descartáveis biodegradáveis, refletindo em uma redução na estrutura de custos para esses materiais e melhorias no meio ambiente.

Com menores tempos de decomposição, as propostas apresentadas acima contribuem para a manutenção de um ambiente sustentável e consciente, onde servidores e os setores institucionais mobilizam esforços em conjunto para construir um ambiente de trabalho e comunitário com a maior capacidade de consumo dos recursos poluentes e, consequentemente, com responsabilidade socioambiental que deles se esperam (GAVIÃO et al., 2017).

Observa-se que, mesmo com os custos de aquisição mais elevados, o retorno das campanhas de conscientização social e da continuidade produzem no ambiente institucional um menor consumo, agressão ambiental e reflexos no orçamento para materiais de consumo dentro da universidade.

Após discutidas as propostas de viabilidade das ações sustentáveis no âmbito do Colegiado Acadêmico de Engenharia Elétrica (CENEL), enquanto modalidade de planejamento prático e de execução subsequente, busca-se conscientizar, em nível micro, os servidores deste setor por meio de construção de campanhas estratégicas com afixação de cartazes enfatizando os impactos da redução do consumo de copos descartáveis e a necessidade de preservação ambiental, colocando o Colegiado na posição de setor com a responsabilidade socioambiental capaz de estimular outras iniciativas.

Em nível macro-institucional, pretende-se desenvolver Relatório Técnico (RT) que subsidie um estudo da viabilidade da substituição dos copos descartáveis pelos outras opções menos agressoras ao meio ambiente, tais quais as apresentadas nas propostas. O Relatório Técnico, em conformidade com Norma Brasileira de Normas Técnicas (ABNT NBR 10719), após devidamente formalizado, será encaminhado à Pró-Reitoria de Planejamento e Desenvolvimento Institucional (Propladi). Os estudos na instituição, evidentemente, podem servir de fundamento para a realização de um conjunto de palestras em outras organizações ou comunidade externa, enfatizando a relevância da redução de consumo de copos descartáveis e das problemáticas que decorrem dessa prática. 


\section{Conclusão}

Parece evidente que viver numa sociedade consumista e que pauta as ações na maximização da produtividade para sustentar exigências dos consumidores, seja em produtos ou prestação de serviços, existem poucas alternativas para minimizar os impactos da exploração desenfreada dos recursos naturais e agressão ao meio ambiente. Viver no contexto que destaca a qualidade sustentável das ações e das políticas públicas exercidas é admirável. Ao menos, ideologicamente falando.

No entanto, os caminhos para a sustentabilidade não é tão simples de se chegar e conquistar quanto se pensa, pelo contrário, é preciso estimular aos poucos a mudança de mentalidade social, incutir nas pessoas a percepção de que estamos sendo sobrecarregados pela irresponsabilidade decorrentes das nossas ganâncias e expectativas. Para agir sustentavelmente é preciso pensar sustentavelmente e, para que essa realidade comece a ser tangível efetivamente no mundo contemporâneo, faz-se necessária a sensibilização e conscientização da humanidade.

Logo, o papel de esclarecimento sobre as vantagens da sustentabilidade e da proteção ambiental para as gerações futuras cabe, dentre os outros componente, às universidades, como disseminadores do saber e da verdade sobre a real situação e sobre as problemáticas de se conquistar a construção de um mundo melhor e sem preocupações tão assustadoras. Observase na educação o caminho formidável para a mudança, sem dúvida alguma.

Enquanto objetivo deste estudo, as ações sustentáveis e as proposições de mudança começam dentro do ambiente acadêmico, começa nos espaços onde a sustentabilidade é semeada com inspiração e paixão que, aos poucos, a sociedade se curva e reconhece a importância do ambiente e suas benesses.

Assim, enquanto um argumento que fundamenta a construção da consciência sustentável, percebe-se dentro da Univasf e dos órgãos internos a competência de motivar iniciativas extraordinárias, resultantes de esforços significativos da proposta de mudança. É por isso que se procura tanto combater com tamanho empenho os grandes desafios que são colocados no caminho: para crescer, é preciso remover as pedras, soltar as amarras que aprisionam os comportamentos irremediáveis das pessoas e capacitá-las para serem semeadoras de "boas novas". 
No âmbito do Colegiado Acadêmico de Engenharia Elétrica (CENEL/Univasf), para o desempenho de suas atividades administrativas, expressou-se o consumo mensal de cerca de 1.000 unidades de copos descartáveis e, anualmente, de 12.000 unidades do mesmo material, implicando em consumo médio mensal de 48 copos descartáveis por servidor deste Colegiado. O custo percentual médio da aquisição dos copos descartáveis dentro do orçamento de material de consumo para o setor varia entre 3\% a 4\%, evidenciando seu valor significativo na estrutura orçamentária, trazendo ainda mais implicações ao meio ambiente, levando em consideração todos os copos descartáveis que são consumidores.

Parece evidente a necessidade de proposição de ações sustentáveis e de um estímulo de conscientização para os servidores, apontando impactos do consumo de copos descartáveis, desenvolvendo internamente a cultura sustentável com a capacidade de motivar e incentivar outros Colegiados Acadêmicos a adotarem os mesmos comportamentos de proteção ambiental e também de racionalidade no uso de recursos.

Nesse sentido, a partir da definição e execução das ações, percebe-se o direcionamento de seus serviços e das atividades para o atendimento da vertentes da Gestão Socioambiental, termo cada vez reproduzido nas empresas, refletindo em efeitos positivos para construção da sociedade mais equilibrada, sustentável e com maior qualidade de vida. Logo, cabe à Universidade avaliar as ações e propostas sustentáveis que contribuam para a construção de um ambiente de trabalho melhor, consciente e responsável, para que, assim, também se alicercem os olhares mais abertos e sensibilizados para as questões de mudança sustentável e social.

\section{Referências}

BOFF, L. Sustentabilidade: o que é-o que não é. Editora Vozes Limitada, 2017.

CARBONARI, M.; PEREIRA, A. A extensão universitária no Brasil, do assistencialismo à sustentabilidade. Revista de Educação, v. 10, n. 10, 2015.

CASTRO, R.; ALMEIDA, B.; SILVA, T. A importância da Sensibilização no programa Agenda Ambiental na Administração Pública (A3P), dentro do Instituto Federal de Educação, Ciência e Tecnologia do Maranhão (IFMA)-Campus Açailândia. In: VII CONNEPICongresso Norte Nordeste de Pesquisa e Inovação. 2012. 
CORRÊA, M.; HEEMANN, A. Proposta de substituição de copos plásticos descartáveis em fábrica de grande porte. MIX Sustentável, v. 2, n. 2, p. 73-79, 2016.

FREITAS, M.; FREITAS, M. Sustentabilidade como paradigma: Cultura, ciência e cidadania. Editora Vozes Limitada, 2016.

GAVIÃO, L.; BARRETO, M.; LIMA; G.; MEZA, L.; SOUZA, D.; VIEIRA, T. Avaliação de eficiência a partir de indicadores de sustentabilidade. Conhecimento \& Diversidade, v. 8, n. 16, p. 68-83, 2017.

GUERRA, A.; FIGUEIREDO, M.; JUNKES, M.; SANTI, A. Ambientalização e sustentabilidade nas universidades: subsídios, reflexões e aprendizagens. Itajaí: Univali, 2015.

MACEDO, J.; QUEIROZ, M.; MARTINS, M.; DINIZ, R.; LIMA, T., MORAIS, C. Estudo do consumo de copos descartáveis no campus Porto Velho Calama e os impactos ambientais e econômicos da substituição dos mesmos. South American Journal of Basic Education, Technical and Technological, v. 2, n. 2, 2016.

MATEUS, R.; BRAGANÇA, L. Avaliação e reconhecimento da sustentabilidade. Construção sustentável: contributo das ferramentas de avaliação, p. 37-86, 2016.

MOTA, S. Responsabilidade social das empresas e sustentabilidade. 2014. Tese de Doutorado. Instituto Superior de Economia e Gestão (ISEG).

MUNCK, L.; BANSI, A.; GALLELI, B. Sustentabilidade em Contexto Organizacional: uma análise comparativa de modelos que propõem trajetórias para sua gestão. Revista de Ciências da Administração, v. 18, n. 44, 2016.

PEREIRA, C.; SILVA, F.; RICKEN, I.; MARCOMIM, F. Percepção e Sensibilização Ambiental como instrumentos à Educação Ambiental. REMEA-Revista Eletrônica do Mestrado em Educação Ambiental, v. 30, n. 2, p. 86-106, 2014.

PROPLADI. PRÓ-REITORIA DE PLANEJAMENTO E DESENVOLVIMENTO INSTITUCIONAL. Material de Consumo e planejamento de compras. 2017. Disponível em: <http://portais.univasf.edu.br/propladi/planejamento/metodologia>. Acesso em: 06 nov. 2017.

SILVA, M. Marketing social interno relacionado a questões ambientais: uma investigação numa instituição federal de ensino superior. 2016. Dissertação de Metrado. Universidade Federal da Bahia (UFBA).

SPOLADORE, Q.; PRATES, K. Diagnóstico ambiental na Secretaria Municipal do Meio Ambiente como subsídio para a elaboração da agenda ambiental. In: II Congresso Brasileiro de Gestão Ambiental. Londrina-PR. 2011. 
UNIVERSIDADE FEDERAL DO VALE DO SÃO FRANCISCO. Agenda Ambiental da Administração Pública (A3P). 2016. Disponível em: < http://portais.univasf.edu.br/sustentabilidade/programa-univasf-sustentavel/a3p>. Acesso em 07 nov. 2017.

UNIVERSIDADE FEDERAL DO VALE DO SÃO FRANCISCO. Plano de Logística Sustentável (PLS). 2016. Disponível em: http://portais.univasf.edu.br/sustentabilidade/programa-univasf-sustentavel/plano-de-logisticasustentavel>. Acesso em: 07 nov. 2017.

UNIVERSIDADE FEDERAL DO VALE DO SÃO FRANCISCO. Relatório do Plano de Logística Sustentável (PLS) - 2016. 2017. Disponível em: < http://portais.univasf.edu.br/sustentabilidade/documentos/RelatriodeAvaliao2016doPLS2.pdf >. Acesso em: 06 nov. 2017.

WARKEN, I.; HENN, V.; ROSA, F. Gestão da sustentabilidade: um estudo sobre o nível de sustentabilidade socioambiental de uma instituição federal de ensino superior. Revista de Gestão, Finanças e Contabilidade, v. 4, n. 3, p. 147, 2014.

YIN, R. Estudo de Caso: Planejamento e método. 2 ed., Bookman, 2001.

\section{Como citar este artigo (Formato ABNT):}

QUIRINO, Cláudio Alberto de Sá; RAMOS, Renatha Dayane C. de A. Ações sustentáveis e suas implicações no trabalho: Uma análise acerca do uso de copos descartáveis. Id on Line Rev.Mult. Psic., 2018, vol.12, n.41, p.390-413. ISSN: 1981-1179.

Recebido: 20/06/2018

Aceito 25/06/2018 